\title{
Establishment of a Competitive Binding Assay Identifying the Different Characteristics of Neutralizing Epitopes of Hepatitis E Virus
}

\author{
Jiyue Wen ${ }^{a}$ Weizhuo Lu ${ }^{c}$ Zhenzhen Liu ${ }^{b}$ Jihong Meng ${ }^{b}$ \\ ${ }^{a}$ Department of Pharmacology, Anhui Medical University, Hefei, China; ${ }^{b}$ Department of Microbiology and \\ Immunology, School of Medicine, Southeast University, Nanjing, China; ' ${ }^{C}$ Hefei Technology College, Hefei, China
}

\section{Keywords}

Hepatitis E virus · Competitive binding assay · Monoclonal antibody · Neutralizing epitope

\begin{abstract}
Aims: To confirm the different characteristics of genotypespecific and common neutralizing epitopes of hepatitis E virus (HEV). Methods: A competitive binding assay was established with known genotype-common neutralizing monoclonal antibodies (mAbs) 3G1 and 5G5 as well as genotype-specific neutralizing mAbs $2 \mathrm{~B} 1$ and 4C5. HEV $\mathrm{ORF}_{2}$ recombinant p166W01 derived from genotype 1 and p166Chn derived from genotype 4 were used as coated antigens, to determine whether the mAbs recognize independent, similar, or overlapping epitopes. mAbs were produced, purified, and conjugated with horseradish peroxidase (HRP). HRP-conjugated 2B1 could react only with p166W01 but not p166Chn, HRP-conjugated 4C5 could react only with p166Chn but not p166W01, while HRP-conjugated $3 \mathrm{G} 1$ and $5 \mathrm{G} 5$ could react both with p166W01 and p166Chn. Thus, competitive binding assays were performed successively using p166W01 and p166Chn antigen. Results and Conclusion: The results of competitive binding assays revealed that the binding of HRP-conjugated 2B1 to p166W01 could not be inhibited by $5 \mathrm{G} 5$ or $3 \mathrm{G} 1$. Similarly, the binding of HRP-
\end{abstract}

conjugated 4C5 to p166Chn could not be inhibited by $5 \mathrm{G} 5$ or 3G1. However, the mAbs $5 \mathrm{G} 5$ and $3 \mathrm{G} 1$ blocked each other's binding to p166W01 and p166Chn, suggesting that common and genotype-specific neutralizing mAbs recognize independent epitopes.

(c) 2018 S. Karger AG, Basel

\section{Introduction}

Hepatitis E virus (HEV) is a nonenveloped, positivestrand RNA virus that is transmitted mainly through the oral route and causes human acute hepatitis $\mathrm{E}[1,2]$. HEV infection can lead to detrimental prognostics, for example life failure, severe acute hepatitis, chronic infection in the organ transplanted and in immunosuppressed patients, and high mortality in pregnant women [3-5]. In addition to confirmed infection in humans, HEVs also infect animals and can be transmitted from animals to human beings; the incidence of hepatitis $\mathrm{E}$ infection in the developed countries has also increased significantly [6]. These findings indicate that $\mathrm{HEV}$ poses a public health threat across the globe [7].

Although one serotype has been recognized, HEV isolates, derived from different areas all over the world, could be classified into 4 major genotypes [8]. HEVs of

\section{KARGER}

(c) 2018 S. Karger AG, Basel

E-Mail karger@karger.com

www.karger.com/int 
genotypes 1 and 2 differ from genotypes 3 and 4 in their epidemiological, antigenic, and immunogenic characteristics [9].

To date, research on antigenic epitope characterization mainly based on the HEV structural protein for an in vitro culture system is unavailable [10]. $\mathrm{pORF}_{2}$ is the major HEV structural protein encoded by $\mathrm{ORF}_{2}$, which is 1 of 3 overlapping open reading frames (ORFs) of the viral genome [5]. Predominant immunogenic regions of $\mathrm{pORF}_{2}$ have been localized at the C-terminal $2 / 3$ region, which were the main targets of vaccine development [11].

Our previous study has revealed the existence of an immunogenicity difference between the hepatitis $\mathrm{E}$ vaccine p179 (439-617 amino acids of the $\mathrm{ORF}_{2}$ protein) derived from genotype 4 and p 239 (Hecolin) derived from genotype 1 , the difference may be attributed to the presence of HEV genotype-specific epitope(s) [9]. Monoclonal antibodies ( $\mathrm{mAbs}$ ) produced in mice immunized respectively with p166Sar (452-617 amino acids of the $\mathrm{ORF}_{2}$ protein) derived from genotype 1 and $\mathrm{p} 166 \mathrm{Chn}$ derived from genotype 4 have been used to confirm the presence of genotype-specific epitope(s). Besides 2 genotype-common neutralizing mAbs, $3 \mathrm{G} 1$ and $5 \mathrm{G} 5,2$ genotype-specific neutralizing $\mathrm{mAbs}, 2 \mathrm{~B} 1$ and $4 \mathrm{C} 5$, were also obtained. $2 \mathrm{~B} 1$ against p166Sar could specifically bind to genotypes 1 and 2 recombinant proteins and neutralized only genotypes 1 and 2 strains in vitro; 4C5 against p166Chn immunoreacted specifically against genotypes 3 and 4 recombinant proteins and neutralized only genotype 3 and 4 strains, while 3G1 against p166Sar and 5G5 against p166Chn could bind to genotypes 1-4 recombinant proteins and neutralized 4 genotype strains [9]. For further study of the different characteristics of genotype-common and genotype-specific neutralizing epitopes of $\mathrm{HEV}$, a competitive binding assay was developed using $\mathrm{mAbs} 2 \mathrm{~B} 1,3 \mathrm{G} 1,4 \mathrm{C} 5$, and 5G5, to confirm whether epitopes recognized by $\mathrm{mAbs}$ are independent, similar, or overlapping.

\section{Materials and Methods}

\section{Recombinant Proteins}

Recombinant p166 was a truncated protein of $\mathrm{pORF}_{2}$, the nucleotide sequences were derived from the following HEV strains: W01 (genotype 1, JX857689) and China-9829 (genotype 4, AY789225). Recombinant plasmids were constructed and expressed in Escherichia coli $[10,12,13]$. The 2 His-tagged p166 proteins were designated as p166W01 and p166Chn, respectively.

mAb Production

A total of 4 neutralizing mAbs, 2B1, 3G1, 4C5, and 5G5 described previously, were used to develop a competitive enzyme- linked immunosorbent assay (ELISA). 2B1 and 3G1 were raised against p166Sar; 4C5 and 5G5 were raised against p166Chn [9]. The $\mathrm{mAbs}$ were produced by injecting $10^{6}$ hybridoma cells into the peritoneal cavity of a BALB/C mouse; ascites fluid containing mAbs was harvested after 7-10 days, filtered, centrifuged, and stored at $-80^{\circ} \mathrm{C}[14]$.

\section{Purification of $m A b s$}

The $\mathrm{mAb}$ ascites fluid was purified using protein $\mathrm{G}$-sepharose column affinity chromatography (Sigma, Germany). Fractions containing antibody were collected using the acidic elution buffer (0.1 M glycine-HCl, pH 2.8) from the immobilized protein $\mathrm{G}$ and then determined at $280 \mathrm{~nm}$; absorbance at $280 \mathrm{~nm}$ (A280) can be used to roughly quantify the mAbs. Sodium dodecyl sulfate polyacrylamide gel electrophoresis was used to confirm and quantify the purified fractions using bovine serum albumin $[15,16]$.

\section{Coupling of Horseradish Peroxidase to $m A b s$}

Purified $\mathrm{mAbs}$ were dialyzed against $100 \mathrm{mM}$ carbonate/bicarbonate buffer ( $\mathrm{pH} \mathrm{9.3)} \mathrm{at} 4{ }^{\circ} \mathrm{C}$ overnight [17]. Antibodies were coupled to horseradish peroxidase (HRP) by the manufacturer's instructions (KPL). About $1.5 \mathrm{mg}$ of HRP was mixed with $0.5 \mathrm{mg}$ of $\mathrm{mAb}$ in $0.5 \mathrm{~mL}$ total volume of HRP conjugation buffer, by gently stirring at room temperature for $1 \mathrm{~h}$. The mixture was left at room temperature for $15 \mathrm{~min}$ after having added $10 \mu \mathrm{l}$ of the reducing agent, and then, 1 volume of distilled glycerol was added for storage and further use.

\section{Cross-Reactivity of HRP-Conjugated mAbs to Heterologous} p166 Antigen

The ELISA method was applied to confirm the cross-reactivity of HRP-conjugated mAbs with p166W01 and p166Chn antigen [9]. Briefly, wells of microplates were coated with $100 \mathrm{ng}$ of the p166W01 and p166Chn antigen, respectively, incubated for $2 \mathrm{~h}$ at $37^{\circ} \mathrm{C}$. This was followed by removal of coated antigens; $200 \mu \mathrm{L}$ of phosphate-buffered saline (PBS) containing $0.1 \%$ bovine serum albumin were added in wells, and then microplates were incubated at room temperature with gentle shaking. Two hours later, the blocking buffer was discarded, and the wells were washed twice with PBS containing 0.05\% Tween-20 (PBST). Serial 2-fold dilutions of HRP-conjugated mAbs ranging from 1:400 to 1:25,600 in $1 \%$ casein PBS were added in corresponding wells, followed by 45 min of incubation at $37^{\circ} \mathrm{C}$; casein PBS was removed by washing 5 times with PBST. Tetramethylbenzidine liquid substrate was added for color development for incubation at $37^{\circ} \mathrm{C}$ for $10 \mathrm{~min}$. Finally, the optical density (OD) of each well was read at $450 \mathrm{~nm}$, with a 630-nm reference wavelength.

\section{Determination of Antigen and $m A b$ Titers}

The titers of antigen and mAbs were determined using an ELISA. Initially, serial 2-fold dilutions of HRP-conjugated mAbs ranging from $1: 400$ to $1: 25,600$ in $1 \%$ casein PBS were prepared, then added to wells precoated with serial dilutions of p166W01 or p166Chn antigen. Followed by a $45-$ min incubation at $37^{\circ} \mathrm{C}$, unbound $\mathrm{mAbs}$ were removed by washing 5 times with PBST. Tetramethylbenzidine liquid substrate was added for color development for a 10 -min incubation at $37^{\circ} \mathrm{C}$. Finally, the OD of each well was read at $450 \mathrm{~nm}$, with a $630-\mathrm{nm}$ reference wavelength, to determine the dilution that was subsaturating and gave an OD reading of approximately 1.0 at $450 \mathrm{~nm}$, with a $630-\mathrm{nm}$ reference wavelength. 
Fig. 1. Reactions with the 2 p166 proteins p166W01 (a) and p166Chn (b) at different $\mathrm{mAb}$ dilutions.

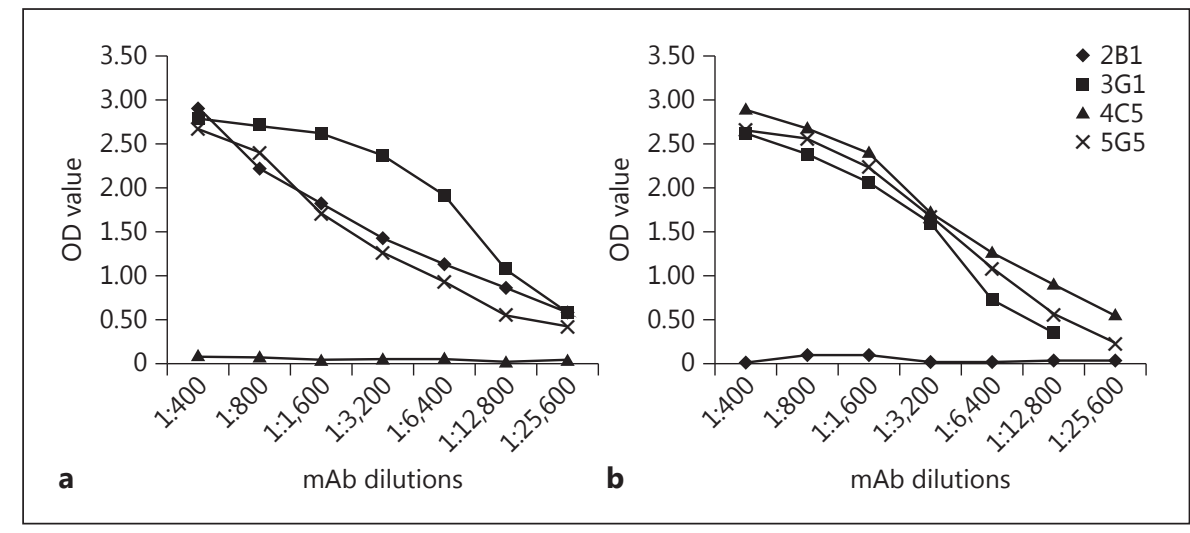

Competitive Binding Assay

The different characteristics of common and genotype-specific neutralizing epitopes of HEV were investigated using a pairwise competitive binding assay established with common and genotype-specific neutralizing mAbs [18]. The methods were similar to the procedures described above, except that p166W01 and p166Chn were used as the coating antigen, respectively, and mixtures of HRP-conjugated $\mathrm{mAb}$ at twice the concentration and a saturated concentration of unconjugated $\mathrm{mAb}$ were added to the coated wells. The OD was measured at $450 \mathrm{~nm}$, with a $630-\mathrm{nm}$ reference wavelength. The percentage inhibition was calculated using the formula: $100 \times\left[1-\left(\mathrm{A}_{450,630}\right.\right.$ of $\mathrm{HRP}-\mathrm{mAb}$ and $\left.\mathrm{mAb}\right) /\left(\mathrm{A}_{450,630}\right.$ of HRP-mAb)]. Competition was rated as positive if the inhibition percentage was more than $50 \%$.

\section{Results}

Cross-Reactivity of HRP-Conjugated mAbs to

Heterologous p166 Antigen

The ELISA method was applied to evaluate the crossreactivity of HRP-conjugated $\mathrm{mAbs}$ to p166W01 and p166Chn antigens. The results revealed that HRP-conjugated $2 \mathrm{~B} 1$ at dilutions from 1:400 to 1:25,600 reacted only with p166W01, but not with p166Chn, and HRP-conjugated 4C5 at dilutions from 1:400 to 1:25,600 reacted only with p166Chn. In contrast, HRP-conjugated 3G1 and 5G5 at dilutions from 1:400 to 1:25,600 reacted well with the 2 p166 proteins (Fig. 1). These observations were similar to the previous findings, $2 \mathrm{~B} 1$ and $4 \mathrm{C} 5$ are genotype-specific $\mathrm{mAbs}$, while 3G1 and 5G5 are genotype-common mAbs [9].

\section{Determination of p166W01 Antigen and}

HRP-Conjugated $m A b$ Titers for the Competitive

Binding Assay

p166W01 antigen was used to establish the competitive binding assay of mAbs 2B1, 3G1, and 5G5; the prop- er titers of mAbs and antigen were determined using ELISA. As shown in Table 1, after square titration, when the dilution of the p166W01 antigen was 1:400, HRPconjugated $2 \mathrm{~B} 1$ was 1:6,400, the mean OD value was close to 1.0. Meanwhile, as shown in Table 2, when the dilution of antigen was 1:400, HRP-conjugated 5G5 and HRPconjugated $3 \mathrm{G} 1$ were $1: 6,400$ and $1: 12,800$, respectively, and the mean OD value was close to 1.0.

\section{Determination of p166Chn Antigen and}

HRP-Conjugated $m A b$ Titers for the Competitive

Binding Assay

p166Chn antigen was used to establish the competitive binding assay of $\mathrm{mAbs} 4 \mathrm{C} 5,3 \mathrm{G} 1$, and $5 \mathrm{G} 5$, the proper titers of $\mathrm{mAbs}$ and antigen were also determined using ELISA. As shown in Table 3, after square titration, when the dilution of the p166Chn antigen was 1:800, HRP-conjugated $4 \mathrm{C} 5$ was $1: 6,400$, and the mean OD value was close to 1.0. Meanwhile, as shown in Table 4, when the dilution of the antigen was 1:800, the dilutions of HRP-conjugated 5 G5 and HRP-conjugated 3G1 were 1:6,400 and 1:12,800, respectively; the mean $\mathrm{OD}$ value was close to 1.0.

\section{Inhibition of Binding of $m A$ bs to p166W01}

The results of inhibition are shown in Table 5; the binding of HRP-conjugated 2B1 to p166W01 antigen was inhibited by unconjugated 2B1 with $68 \%$ inhibition. There was no significant inhibition between 2B1 with mAbs 5G5 and 3G1 (27 and 30\%). More complete inhibition was obtained from heterologous $\mathrm{mAbs} 3 \mathrm{G} 1$ and $5 \mathrm{G} 5$, for the binding of HRP-3G1 to antigen was inhibited by 5 G5 with $61 \%$ inhibition, HRP-conjugated 5G5 to antigen was inhibited by $3 \mathrm{G} 1$ with $99 \%$ inhibition. Binding of HRP-3G1 and HRP-5G5 to p166W01 antigen was also almost completely inhibited by themselves ( 81 and $80 \%$ 
Table 1. Determination of p166W01 antigen and HRP-conjugated mAb titers

\begin{tabular}{lllllllll}
\hline $\begin{array}{l}\text { Antigen } \\
\text { dilution }\end{array}$ & \multicolumn{2}{l}{ Dilution of HRP-conjugated 2B1 } \\
\cline { 2 - 8 } & $1: 400$ & $1: 800$ & $1: 1,600$ & $1: 3,200$ & $1: 6,400$ & $1: 12,800$ & $1: 25,600$ & negative control \\
\hline $1: 200$ & 2.900 & 2.225 & 1.827 & 1.432 & 1.138 & 0.876 & 0.595 & 0.076 \\
$1: 400$ & 2.782 & 1.754 & 1.512 & 1.238 & 0.958 & 0.703 & 0.354 & 0.061 \\
$1: 800$ & 1.945 & 1.301 & 1.105 & 0.867 & 0.775 & 0.432 & 0.216 & 0.034 \\
$1: 1,600$ & 1.065 & 0.720 & 0.856 & 0.662 & 0.543 & 0.245 & 0.098 & 0.090 \\
$1: 3,200$ & 0.832 & 0.553 & 0.356 & 0.213 & 0.115 & 0.075 & 0.034 & 0.034 \\
$1: 6,400$ & 0.612 & 0.298 & 0.232 & 0.156 & 0.089 & 0.054 & 0.022 & 0.023 \\
\hline
\end{tabular}

The OD value in italics is significant, i.e. close to 1 .

Table 2. Determination of p166W01 antigen and HRP-conjugated mAb titers

\begin{tabular}{lllllllll}
\hline HRP-mAbs & \multicolumn{7}{l}{ Dilution of HRP-conjugated mAbs } \\
\cline { 2 - 8 } & $1: 400$ & $1: 800$ & $1: 1600$ & $1: 3,200$ & $1: 6,400$ & $1: 12,800$ & $1: 25,600$ & negative control \\
\hline HRP-5G5 & 2.659 & 2.573 & 2.248 & 1.665 & 1.093 & 0.565 & 0.241 & 0.069 \\
HRP-3G1 & 2.784 & 2.713 & 2.618 & 2.363 & 1.924 & 1.077 & 0.583 & 0.052 \\
\hline
\end{tabular}

The OD values in italics are significant, i.e. close to 1 .

Table 3. Determination of p166Chn antigen and HRP-conjugated mAb titers

\begin{tabular}{|c|c|c|c|c|c|c|c|c|}
\hline $1: 400$ & 2.759 & 2.562 & 2.343 & 1.532 & 1.057 & 0.866 & 0.410 & 0.045 \\
\hline $1: 800$ & 2.309 & 1.953 & 1.721 & 1.420 & 0.956 & 0.652 & 0.350 & 0.056 \\
\hline $1: 1,600$ & 1.897 & 1.722 & 1.456 & 1.232 & 0.832 & 0.563 & 0.298 & 0.073 \\
\hline
\end{tabular}

The OD value in italics is significant, i.e. close to 1 .

Table 4. Determination of p166W01 antigen and HRP-conjugated mAb titers

\begin{tabular}{|c|c|c|c|c|c|c|c|c|}
\hline HRP-mAbs & $1: 400$ & $1: 800$ & $1: 1,600$ & $1: 3,200$ & $1: 6,400$ & $1: 12,800$ & $1: 25,600$ & negative control \\
\hline HRP-3G1 & 2.841 & 2.641 & 2.312 & 1.956 & 1.494 & 0.908 & 0.556 & 0.042 \\
\hline
\end{tabular}

The OD values in italics are significant, i.e. close to 1 . 
Table 5. Percentage inhibition of binding of HRP-mAbs to p166W01

\begin{tabular}{llll}
\hline Antigens/ & \multicolumn{3}{l}{ Unlabeled mAbs } \\
\cline { 2 - 4 } HRP-mAbs & $5 \mathrm{G} 5$ & $3 \mathrm{G} 1$ & 2B1 (or 4C5) \\
\hline p166W01 & & & \\
HRP-5G5 & 80 & 99 & 7.5 \\
HRP-3G1 & 61 & 81 & 29 \\
HRP-2B1 & 27 & 30 & 68 \\
p166Chn & & & \\
HRP-5G5 & 61 & 76 & 7.3 \\
HRP-3G1 & 65 & 69 & 6.8 \\
HRP-4C5 & 25 & 30 & 69 \\
\hline
\end{tabular}

inhibition). These results suggest that $3 \mathrm{G} 1$ and $5 \mathrm{G} 5$ may share the same epitope or overlapping epitope, yet 2B1 probably recognizes a different epitope.

\section{Inhibition of Binding of mAbs to p166Chn}

The results of inhibition are shown in Table 5: the binding of HRP-4C5 to p166Chn was inhibited by unconjugated 4C5 with $69 \%$ inhibition, there was no significant inhibition ( 25 and 30\%) obtained from the other 2 unconjugated mAbs 3G1 and 4C5. However, a higher inhibition rate was obtained from $\mathrm{HRP}$-conjugated $\mathrm{mAbs}$ 3G1 and 5G5 binding to antigen, inhibited by unconjugated 5G5 and 3G1 with 65 and $76 \%$ inhibition. Binding of HRP-conjugated 3G1 and HRP-conjugated 5G5 to p166Chn antigen was also almost inhibited by themselves. These results also suggest that 3G1 and 5G5 may share the same epitope or overlapping epitope, while 4C5 probably recognizes a different epitope.

\section{Discussion}

Since the novel swine HEV was first isolated [19], antiHEV antibodies have been reported in many animals, revealed HEV infection among animals and human beings, and this may be transmitted from animals to human beings $[20,21]$. The reduction of hepatitis E morbidity and mortality depended on vaccine prevention and effective diagnosis. Knowledge of epitopes of HEV was essential for vaccine preparation and diagnostic development [22]. The detection of specific antibodies in serum is one of the main diagnostic methods, and there is a growing number of serological assays for antibody detection. However, the assays used to detect specific antibodies vary considerably in sensitivity [23]. Some commercial diagnostic assays based on genotype 1 or 2 antigens fail to detect serum an-

Different Characteristics of Neutralizing

Epitopes of HEVs tibodies against genotypes 3 or 4 isolates [24]. Little is known about the mechanisms underlying the noncorrespondence of the different diagnostic assays.

At present, an in vitro cell culture system is still unavailable for HEV research. Therefore, $\mathrm{pORF}_{2}$ containing most immunogenic sites has been widely used for HEV immunological study, with a conformation-dependent character [25]. The structural basis of an immunogen to elicit neutralizing and protective antibodies is the neutralizing epitope, which is the main target of hepatitis $\mathrm{E}$ vaccine development [22]. We have previously reported that the $\mathrm{p} 166$ protein, a truncated protein of $\mathrm{pORF}_{2}$, can model $\mathrm{HEV}$ neutralizating epitope(s), and antibodies raised against p166 could crossneutralize different genotypes of HEV [26]. In addition, hepatitis E p239 vaccine derived from genotype $1 \mathrm{HEV}$ was effective in a phase 3 clinical trial conducted in Jiangsu Province, China, where the epidemic HEV isolate is genotype 4 [27]. These findings revealed common neutralizing epitope(s) exist within the different genotypes of HEV. Besides the common neutralizing epitope(s), genotype-specific epitope(s) has also been confirmed to exist, for $\mathrm{mAb}$ preparation and characterization $[9,26]$.

To further identify the characterization of common and genotype-specific neutralizing epitopes, the competitive inhibition assay was established with common neutralizing $\mathrm{mAbs}, 3 \mathrm{G} 1$ and 5G5, and genotype-specific neutralizing $\mathrm{mAbs}, 2 \mathrm{~B} 1$ and $4 \mathrm{C} 5$, to investigate the competition binding to p166W01 or p166Chn antigen and to determine whether the mAbs recognize independent, similar, or overlapping epitopes.

Initially, ascitic fluids of mAbs 3G1, 2B1, 5G5, and 4C5 were produced, purified, and conjugated with HRP. The ELISA method was applied to compare the binding affinity of HRP-conjugated mAbs with different genotypes of HEV p166. The results revealed that HRP-conjugated $2 \mathrm{~B} 1$ only reacted with genotype 1 p166W01, but not p166Chn. Similarly, HRP-conjugated 4C5 reacted only with p166Chn. In contrast, HRP-conjugated 3G1 and 5G5 reacted well against the 2 genotype 166 proteins. So, competitive binding assays are based on the genotype 1 and 4 HEV p166 antigens. The results of competitive binding assays are not surprising, i.e. that the binding of $2 \mathrm{~B} 1$ to p166W01 only competed by itself, while $3 \mathrm{G} 1$ and 5G5 could compete each other for the binding to p166W01. Moreover, the binding of 4C5 to p166Chn was similarly only competed by itself, but 3G1 and 5G5 could compete each other for the binding to p166Chn. These findings indicated that $3 \mathrm{G} 1$ and $5 \mathrm{G} 5$ recognize the same or overlapping epitopes and that $2 \mathrm{~B} 1$ and $4 \mathrm{C} 5$ recognize different ones. 
This is the first study that investigates the different characteristics of genotype-common and genotype-specific conformational neutralizing epitopes of HEV. We demonstrated that common and genotype-specific neutralizing epitopes may be independent. This discovery is very beneficial to demonstrate the mechanisms underlying the low concordance of the different diagnostic assays. Further studies are of crucial importance to elucidate the different characteristics of neutralizing epitopes of HEV in the effectiveness of diagnostic development and vaccine preparation.

\section{Acknowledgment}

This work was supported by the doctoral scientific research foundation of Anhui Medical University (No. 0110037101).

\section{Disclosure Statement}

The authors declare no conflicts of interest.

\section{References}

1 Debing Y, Moradpour D, Neyts J, Gouttenoire $\mathrm{J}$ : Update on hepatitis E virology: implications for clinical practice. J Hepatol 2016;65:200-212.

$\checkmark 2$ Oh HW, Cha RR, Lee SS, Lee CM, Kim WS, Jo YW, Kim JJ, Lee JM, Kim HJ, Ha CY, Kim HJ, Kim TH, Jung WT, Lee OJ: Comparing the clinical features and outcomes of acute hepatitis $E$ viral infections with those of acute hepatitis A, B, and C infections in Korea. Intervirology 2017;60:109-117.

- 3 Verma N, Sharma M, Biswal M, Taneja S, Batra $\mathrm{N}$, Kumar A, Dhiman RK: Hepatitis E virus induced acute liver failure with scrub typhus coinfection in a pregnant woman. J Clin Exp Hepatol 2017;7:158-160.

-4 Zhou X, de Man RA, de Knegt RJ, Metselaar HJ, Peppelenbosch MP, Pan Q: Epidemiology and management of chronic hepatitis $\mathrm{E}$ infection in solid organ transplantation: a comprehensive literature review. Rev Med Virol 2013; 23:295-304.

5 Mushahwar IK: Hepatitis E virus: molecular virology, clinical features, diagnosis, transmission, epidemiology, and prevention. J Med Virol 2008;80:646-658.

-6 Bouwknegt M, Rutjes SA, Reusken CB, Stockhofe-Zurwieden N, Frankena K, de Jong MC, de Roda Husman AM, Poel WH: The course of hepatitis $\mathrm{E}$ virus infection in pigs after contactinfection and intravenous inoculation. BMC Vet Res 2009;5:7.

7 Haider N, Khan MSU, Hossain MB, Sazzad HMS, Rahman MZ, Ahmed F, Zeidner NS: Serological evidence of hepatitis $\mathrm{E}$ virus infection in pigs and jaundice among pig handlers in Bangladesh. Zoonoses Public Health 2017;64: 572-577.

8 Nan Y, Zhang YJ: Molecular biology and infection of hepatitis E virus. Front Microbiol 2016; 7:1419.

-9 Wen J, Behloul N, Dai X, Dong C, Liang J, Zhang $M$, Shi C, Meng J: Immunogenicity difference between two hepatitis $\mathrm{E}$ vaccines derived from genotype 1 and 4 . Antiviral Res 2016;128:36-42.
10 Zhang H, Dai X, Shan X, Meng J: Characterization of antigenic epitopes of the ORF2 protein from hepatitis $\mathrm{E}$ virus genotype 4. Virus Res 2009;142:140-143.

11 Behloul N, Wen J, Dai X, Dong C, Meng J: Antigenic composition and immunoreactivity differences between HEV recombinant capsid proteins generated from different genotypes. Infect Genet Evol 2015;34:211-220.

12 Liang JH, Dai X, Dong C, Meng JH: A single amino acid substitution changes antigenicity of ORF2-encoded proteins of hepatitis E virus. Int J Mol Sci 2010;11:2962-2975.

13 Behloul N, Zhang M, Meng J: Binding preference of anti-HEV antibodies in sera collected in Algeria for antigens derived from HEV genotype 1. Hepat Mon 2016;16:e35312.

14 Liang JH, Liang LM, Dong M, Han ZG, Dong C, Meng JH: Identification of a novel antigenic epitope on GST fusion-expressed and ORF2encoded proteins of hepatitis $\mathrm{E}$ virus (in Chinese). Xi Bao Yu Fen Zi Mian Yi Xue Za Zhi 2008;24:321-323, 327.

15 Zhang J, Dong M, Jiang B, Dai X, Meng J: Antigenic characteristics of the complete and truncated capsid protein VP1 of enterovirus 71. Virus Res 2012;167:337-342.

16 Xu M, Behloul N, Wen J, Zhang J, Meng J: Role of asparagine at position 562 in dimerization and immunogenicity of the hepatitis $\mathrm{E}$ virus capsid protein. Infect Genet Evol 2016;37:99107.

17 Lindstrom NM, Call DR, House ML, Moffitt $\mathrm{CM}$, Cain KD: A quantitative enzyme-linked immunosorbent assay and filtration-based fluorescent antibody test as potential tools to screen broodstock for infection with Flavobacterium psychrophilum. J Aquat Anim Health 2009;21:43-56.

$\checkmark 18$ Zhou EM, Guo H, Huang FF, Sun ZF, Meng $\mathrm{XJ}$ : Identification of two neutralization epitopes on the capsid protein of avian hepatitis $\mathrm{E}$ virus. J Gen Virol 2008;89:500-508.

19 Meng XJ, Purcell RH, Halbur PG, Lehman JR, Webb DM, Tsareva TS, Haynes JS, Thacker BJ,
Emerson SU: A novel virus in swine is closely related to the human hepatitis E virus. Proc Natl Acad Sci USA 1997;94:9860-9865.

20 Caprioli A, Ostanello F, Martelli F: Hepatitis E virus: an emerging zoonotic agent. Vet Ital 2005;41:113-127.

21 Park WJ, Park BJ, Ahn HS, Lee JB, Park SY, Song CS, Lee SW, Yoo HS, Choi IS: Hepatitis $\mathrm{E}$ virus as an emerging zoonotic pathogen. J Vet Sci 2016;17:1-11.

22 Gu Y, Tang X, Zhang X, Song C, Zheng M, Wang K, Zhang J, Ng MH, Hew CL, Li S, Xia $\mathrm{N}$, Sivaraman J: Structural basis for the neutralization of hepatitis $\mathrm{E}$ virus by a cross-genotype antibody. Cell Res 2015;25:604-620.

23 Vollmer T, Diekmann J, Eberhardt M, Knabbe C, Dreier J: Monitoring of anti-hepatitis E virus antibody seroconversion in asymptomatically infected blood donors: systematic comparison of nine commercial anti-HEV IgM and IgG assays. Viruses 2016;8:232.

24 Bendall R, Ellis V, Ijaz S, Thurairajah P, Dalton HR: Serological response to hepatitis E virus genotype 3 infection: IgG quantitation, avidity, and IgM response. J Med Virol 2008;80:95-101.

-25 Zhao M, Li XJ, Tang ZM, Yang F, Wang SL, Cai W, Zhang K, Xia NS, Zheng ZZ: A comprehensive study of neutralizing antigenic sites on the hepatitis E virus (HEV) capsid by constructing, clustering, and characterizing a tool box. J Biol Chem 2015;290:19910-19922.

26 Meng J, Dai X, Chang JC, Lopareva E, Pillot J, Fields HA, Khudyakov YE: Identification and characterization of the neutralization epitope(s) of the hepatitis E virus. Virology 2001; 288:203-211.

27 Zhu FC, Zhang J, Zhang XF, Zhou C, Wang ZZ, Huang SJ, Wang H, Yang CL, Jiang HM, Cai JP, Wang YJ, Ai X, Hu YM, Tang Q, Yao X, Yan Q, Xian YL, Wu T, Li YM, Miao J, Ng $\mathrm{MH}$, Shih JW, Xia NS: Efficacy and safety of a recombinant hepatitis $\mathrm{E}$ vaccine in healthy adults: a large-scale, randomised, double-blind placebo-controlled, phase 3 trial. Lancet 2010; 376:895-902. 